From 1971 to 1993 the fraction of the Hong Kong population aged 65 or athos dere-published version more than doubled from 4.5 percent to 9.2 percent. By official estimates, this fraction is projected to rise further to 12.3 percent by the year 2011. An aging demographic structure has important effects on labor supply. The labor force participation rate for men aged 25 or above was 92 percent in 1971; it fell to 83 percent in 1993. Since elderly people have a much lower labor force attachment than younger people, a shift of the population structure towards more old people would reduce the aggregate labor force participation rate. Another reason behind the decline in overall labor force participation rate was the substantial fall in labor force participation among the elderly. While the labor force participation rate for men between 25 and 44 years old remained stable at 98 percent from 1971 to 1993, the participation rate among men aged 65 or above dropped sharply from 40 percent to 17 percent during the same period. ${ }^{1}$ These figures indicate that most adjustments in male labor supply occurred during old age. ${ }^{2}$ Studying the labor supply behavior of elderly men is an essential component towards understanding the changes in labor supply in Hong Kong.

Studies of male labor supply often find that the number of hours or weeks worked in a year is relatively insensitive to wages and income (see, for example, Pencavel's (1986) survey paper). However the hours or weeks decision is only one dimension of labor supply; an equally important dimension is the length of the working life. If the difference between the market wage rate and the value of leisure is higher for prime age men than for elderly men, people will tend to bunch their leisure consumption towards the end of their life. The depreciation of human capital also makes an intermittent attachment to the labor force unattractive. As a result, in the choice of the number of years to work, men often adopt a cut-off rule whereby they remain in the labor force continuously until a certain age, after which they stay retired for the rest of their life. With this type of behavior, the retirement age becomes a crucial indicator of lifetime labor supply. Unfortunately systematic information about the age at retirement is not directly available from existing survey data in Hong Kong. For example, census records only contain information about the current retirement status of respondents, not the date 
of their retirement. This paper attempts to estimate the retirement age from retirement status using a censored regression approach.

Little empirical research on labor supply in Hong Kong has been done. Lam and Liu (1995a) discuss labor supply in Hong Kong at the aggregate level. Lam and Liu (1995b) and Suen (1994) use census micro-data to study labor force participation of married women. The present paper is the first econometric study of male labor supply behavior in Hong Kong. This paper focuses on the retirement age as opposed to more conventional measures of labor supply. The Hong Kong population censuses contain no information about the number of weeks worked in a year. A question on the number of hours worked in the past week was asked in the 1976, 1981 and 1986 censuses, but this question was dropped from the 1991 census. Moreover the censuses only ask respondents to report their employment earnings in the previous month. Besides the usual problem that measurement errors in the hours variable will induce a negative correlation between hours worked and average hourly earnings, the measurement problem is compounded by the fact that the hours variable and the earnings variable refer to different time frames. Therefore it is very difficult to obtain reliable data on wage rates. The present study sidesteps these issues by concentrating on the more permanent aspects of lifetime labor supply.

The study of retirement patterns is of interest not only as an important component of the research on labor supply behavior in Hong Kong, but also because of its relevance to public policy. Perhaps the most noteworthy is the issue of income maintenance at old age. Although the data used in this study will not allow an evaluation of how pension wealth affects retirement incentives, knowledge about the average retirement age and its variability and trend are useful inputs to the design of a public pension system. Another potential use of the results is in personal injury cases, where the assessment of lost earnings depends on the number of years the person is expected to work were it not for the injury. As there is no published figure on retirement age, measuring the expected length of working life is difficult. The censored regression model used here will be useful towards establishing a reasonable estimate. 


\section{Retirement in Hong Kong: Definition and Patterns}

In Hong Kong retirement can either be the result of a voluntary withdrawal from the labor force or be initiated by mandatory retirement provisions in the employment contract. The civil service, for example, sets the retirement age at 60, though early retirement and extension of service are possible. Mandatory retirement is also common (but by no means universal) among the larger companies in Hong Kong. Unlike most developed countries, Hong Kong does not have a social security system or a compulsory provident fund. However all government employees are entitled to pension benefits. In the early 1990s, about 26 percent of the private sector production workers were covered by some kind of company pension schemes. At the administrative and managerial level, this proportion was 77 percent (Suen 1996). Private pension coverage is less extensive in the 1970s and 1980s. The Hong Kong government has recently passed legislation that would mandate all employees and employers to contribute to approved private pension schemes with effect from 1997. In the period under study, the elderly have to rely on private pensions, past savings, and their children for old-age support. The latter is believed to be particularly important for a Chinese society like Hong Kong, although hard data on adult children's contributions to their parents are difficult to come by.

There are many possible ways to define retirement, but the empirical definition of retirement status is often imposed by the nature of the available data. In the United States, research that makes use of administrative records (e.g., Mitchell and Fields 1984; Gendell and Siegel 1992) often defines retirement in terms of the receipt of company pensions or social security payments. For studies that use survey data (e.g., Murray 1972; Hurd and Boskin 1984; Slade 1987), individuals may be classified as retired if they give an affirmative answer to a question like: "Are you currently retired?" Such classification depends on the implicit definition of retirement adopted by the survey respondent. Lazear (1986, p. 310) suggests that if the primary interest is in discussing patterns of labor force participation, an appropriate definition of a retired person is one who "is out of the labor force with the intention of remaining out permanently." Pensioners, social security recipients, and people who think they are "retired" according 
to their own subjective evaluation need not be out of the labor force.

The definition of retirement adopted here ensures that a "retired person" is not in the labor force. In Hong Kong's population censuses, there is no question that directly asks whether the respondent is currently retired, but there is a question which requests the respondent to supply a reason for not seeking work. The response is coded into several categories: (a) temporary sickness/injury; (b) household duty; (c) studying; (d) of independent means; (e) retirement (including pensioner); (f) inmates of institutions; and $(\mathrm{g})$ others. Individuals whose response falls into these seven categories are classified as economically inactive (i.e., not in the labor force). Other responses are possible: (h) waiting to take up new work; (i) expected to return to original work; or (j) believed no work is available. Individuals whose response belongs to the latter three categories are classified as unemployed. In this study, a person is defined to be "retired" if his reason for not seeking work is either (d) or (e). Since only those who do not have a job and who are not seeking work are asked to give a reason for not seeking work, this definition ensures that a retired person is not in the labor force.

Table 1 shows the distribution of the various reasons for not seeking work among the economically inactive population (aged 40 or above) in 1991. Among females, a sizable proportion were not seeking work because of household duties. Some of them might have worked before and have retired into home-making, some might have never entered the labor force, and others might intend to re-enter the labor force in the future. To avoid ambiguity in the definition of retirement status, this paper only studies the retirement behavior of men. For the purpose of this study, men who were employed or unemployed at the time of the census are considered "not retired." Economically inactive men whose reason for not seeking work is either "retirement" or "of independent means" are considered "retired." 3 Other economically inactive men (e.g., home-makers, persons who were temporarily ill) are dropped from the sample. They make up a relatively minor proportion of the relevant population. ${ }^{4}$

[Table 1 about here]

The main data sets used in this study are the one percent random sample files of 
the 1976, 1981, 1986 and 1991 population censuses. This paper focuses on the adult male population aged 40 or above. People who were not born in Hong Kong or in China (including Macau and Taiwan) are excluded from the analysis. ${ }^{5}$ The resulting samples contain 5863, 6740, 7449, and 8306 observations for the four census years, respectively.

Table 2 shows the percentage of retired men by age group for each of the four census years. Not surprisingly the percent retired generally rise with age. By the time people reached age 65, more than half were retired from the labor force. The overall percentage of retired persons also increased over time, from 15.8 percent in 1976 to 25.6 percent in 1991. Part of this increase was due to an aging population structure: the fraction of elderly people had increased steadily in Hong Kong, and elderly men are more likely to be retired than younger men. Another part of the increase was due to the rise in age-specific retirement rates during the 1980s. Table 3 shows the decomposition of the change in percent retired for different periods into these two factors. The table indicates that changes in population structure alone can account for more than four-fifths of the overall increase in percent retired in the 1976-1991 period. Changes in age-specific retirement rates contributed to about one-fifth of the overall change in percent retired, but the contribution was negative in 1976-1981.

[Tables 2 and 3 about here]

\section{Retirement Age as a Censored Variable}

Riemers (1976) has shown that changes in the percentage of the retired population does not necessarily move in the same direction as changes in the average retirement age. Census questionnaires, however, do not directly ask the date at which a retired person enters into retirement. Fortunately information about the current age of an individual and his current retirement status does contain partial information about the retirement age. If retirement is an absorption state (i.e., people do not re-enter the labor force once they retire), ${ }^{6}$ then the retirement age may be treated as a failure time as in survival models (e.g., Cox and Oakes 1984). In such models the failure times for failed observations are typically known, but the failure times are right-censored for observations that have not yet failed. In the census data sets, the failure time (retirement 
age) is not known even for failed observations (retired persons). Therefore observations on the retirement age are censored on either side.

More specifically, let $y_{i}^{*}$ be the retirement age of individual $i$, and let $A_{i}$ be his age at the time of the census. The retirement age is an unobserved random variable with distribution function $F(\cdot)$. Also let $\mathcal{R}$ be the set of individuals who are retired at the time of the census. Then one can infer:

$$
y_{i}^{*} \begin{cases}\leq A_{i}, & \text { if } i \in \mathcal{R} \\ >A_{i}, & \text { otherwise }\end{cases}
$$

Assume that, conditional on age, attrition from the census due to death or emigration is independent of retirement status. Further assume there is no duration dependence in the retirement decision. Then if $p(A)$ is the sample proportion of the population at age $A$ who are retired at the time of the census, $p(A)$ will give a consistent estimator for $F(A)$. For a non-negative random variable $A$ with distribution function $F(A)$, its expected value can be expressed as $\int_{0}^{\infty} 1-F(A) d A$. Thus a non-parametric estimator for the mean retirement age is

$$
\hat{\mu}=\sum_{A=0}^{T} 1-p(A),
$$

where $T$ is the terminal date. ${ }^{7}$ Since $p(A)$ and $p\left(A^{\prime}\right)$ are independent for any $A \neq A^{\prime}$, the standard error of the above estimator is simply

$$
\left(\sum_{A=0}^{T} \frac{p(A)(1-p(A))}{n(A)}\right)^{1 / 2},
$$

where $n(A)$ is the sample count of the number of individuals at age $A$.

Table 4 shows that the mean retirement age rose slightly from 1976 to 1981 and then declined during the 1980s. The difference in mean retirement age between 1976 and 1991 is 1.4 years, and this difference is statistically significant at the 0.01 level. The population in 1991 were on average better educated than those in 1976; therefore they had entered the labor force at a later age. Assume people stay in the labor force continuously until they retire, the length of the working life can be obtained by subtracting the age at labor force entry from the retirement age. In 1976 the mean lifetime labor supply was 
54.4 years; in 1991 the corresponding figure was 52.1 years. Lifetime male labor supply had therefore fallen about 4 percent in these 15 years.

[Table 4 about here]

The last two rows of Table 4 also show that, thanks to a steady rise in life expectancy, the average length of retirement life increased dramatically from 7.1 years to 13.0 years during this period. This is all the more remarkable as there is no public funding for old-age support in Hong Kong. One can conclude that the secular trend towards earlier retirement is not solely a function of the pension inducement effect; a strong income effect on the demand for leisure must also be at play.

In using the sample proportion of retired persons at a given age to estimate the value of the distribution function at that age, the non-parametric approach ignores the information contained in observations of individuals at other ages. For example, a 55 year old retired person must have a retirement age that is less than 65 . Similarly a 75 year old person who is still economically active must have a retirement age beyond 65 . Using $p(65)$ to estimate $F(65)$ fails to utilize such information from the 55 year olds and the 75 year olds. To fully utilize the information contained in the sample, and to facilitate the use of covariates in the analysis, a parametric approach will be desirable.

In principle the decision to retire can be viewed as an optimal stopping problem. Rust $(1989 ;$ 1990) and Berkovec and Stern (1991), for example, use a dynamic programming approach to model retirement behavior. Slade (1987) detects some state dependence in the retirement decision using longitudinal data. The data used here does not contain any time-varying covariates, so they would preclude any explicit dynamic treatment. Instead the retirement decision is collapsed into a static problem of determining the optimal retirement age. Let $X_{i}$ be a vector of individual characteristics and $\beta$ be the associated coefficients. Assume

$$
y_{i}^{*}=X_{i} \beta+u_{i}
$$

where $u_{i}$ is distributed $N\left(0, \sigma^{2}\right){ }^{8}$ Since $y_{i}^{*}$ is censored according to equation (1), the 
log-likelihood function of the sample observations can be written as

$$
L=\sum_{i \in \mathcal{R}} \log \Phi\left(\frac{A_{i}-X_{i} \beta}{\sigma}\right)+\sum_{i \notin \mathcal{R}} \log \left(1-\Phi\left(\frac{A_{i}-X_{i} \beta}{\sigma}\right)\right)
$$

The parameters can be estimated by a censored regression using the maximum likelihood method.

The log-likelihood function of a censored regression model resembles that of a probit model with the coefficient on the age variable set to minus one. This constraint arises because the current age can be viewed as a censored observation of the retirement age by equation (1). Boskin (1977) and Hurd and Boskin (1984) have studied retirement behavior using the probit and the logit approach. They do not recognize, however, that the structure of the model allows one to identify the coefficient on age a priori.

As far as estimation is concerned, the censored regression approach and the probit approach will give identical values for the likelihood function. Because a censored regression model incorporates an a priori constraint on the coefficient of the age variable, however, it has several advantages over a probit model for parameter identification and interpretation. First, in a probit model, $\sigma$ cannot be identified. On the other hand, in a censored regression model, as long as not all individuals in the sample are of the same age, $\sigma$ is identifiable. Thus the model allows one to estimate the variance of the retirement age. Second, the $\beta$ coefficients are only unique up to a multiplicative constant in a probit model. Under the censored regression approach, since $\sigma$ can be estimated, the $\beta$ coefficients are also uniquely determined. Moreover these $\beta$ coefficients have a ready interpretation: they are the partial derivatives of the retirement age with respect to the $X$ variables. Evaluated at the sample mean value, $\bar{X} \hat{\beta}$ will give an estimate for the mean retirement age of the population.

\section{Model Estimation and Results}

Since retirement is a lifetime labor supply decision, information on wage earnings at one point of the life cycle will be of limited use in predicting the retirement age. In principle the entire wage history of an individual is relevant for the retirement decision. Such 
information is unavailable from the census. ${ }^{9}$ Instead the empirical model uses education and place of birth to predict retirement age, since these two factors are known to shift the position and the shape of the earnings profile. The variable school measures the number of years of schooling. The dummy variable hk is set to 1 for those who were born in Hong Kong, and hk $=0$ for those born in China, Taiwan or Macau.

Non-wage income is measured by two variables, hincome and house. The former variable is obtained by deducting the person's own employment earnings from his household income. ${ }^{10}$ The variable house is a dummy variable indicating that the person lives in a owner-occupied housing unit. It is used as a proxy for household wealth. Another variable that is commonly used in labor supply models is marital status. The variable married is set to 1 for individuals who were married with wife present at the time of the census.

Unlike education or place of birth, the variables hincome, house and married will change with age. The household composition and household income of, say, a 55 year old person may not be directly comparable to those of a 75 year old. To remove the influence of life cycle factors, deviations from age-specific means can be used. For example, the income variable may alternative be defined as the residual from a regression of hincome on a set of dummy variables for each single-year age group from 40 to 87 and for the age group 88 or above. The variables house ownership and marital status variables can similarly be derived using a linear probability model. It turns out, however, that variations in age explain less than 5 percent of the variations in non-wage income, in home ownership or in marital status. Using the original variables (hincome, house and married) in the censored regressions or using the age-adjusted variables makes very little difference to the estimation results. To facilitate the interpretation of parameters, this paper reports results using the original variables.

Hong Kong does not yet have a public pension system, and information on private pensions is not available from any systematic data source. For this reason, the censored regression model estimated in this paper will not be able to address the important issue regarding the effect of pensions on retirement incentives. 
Table 5 displays the estimated censored regression models for the four census years as well as for the combined sample. Although a likelihood ratio test rejects the hypothesis of identical coefficients across equations, the sign patterns of the estimated coefficients are quite similar for the different periods. The variable hincome shows a statistically significant negative income effect on lifetime labor supply. According to the estimates in the last column, a one standard deviation increase in hincome (i.e., HK\$11659 at 1991 prices) will lower the retirement age by 1.13 years on average. Home ownership is also found to lower the retirement age by about one year. The data does not contain information on pension wealth. But the results about income from other household members and household wealth do suggest that higher non-wage income will tend to induce earlier retirement. ${ }^{11}$

[Table 5 about here]

The hincome variable may contain unearned income such as income from savings. It is conceivable that those who planned to retire early have saved more in anticipation, making the causal inference about the wealth effect problematic. To address this issue, I have re-estimated the equations in Table 5 using a new definition of the hincome variable that excludes the person's own unearned income. All the coefficients on this new hincome variable remain highly significant. For example, in the pooled regression, the estimated coefficient on the new hincome variable is -0.094 with a standard error of 0.008 (the original estimate is -0.097 ).

The estimated coefficients for the variable married shows that married men with wife present on average retire eight months later than other men, although three out of four coefficients are not statistically significant for the individual census years.

Curiously, the variable school is found to raise the retirement age while the variable hk is found to lower it, although both variables are associated with higher wage rates. In general, because of counteracting income and substitution effects, a higher level of permanent wage will have ambiguous effect on lifetime labor supply. Nevertheless the opposite effects of education and place of birth on the retirement age still deserves an explanation. In a life cycle framework, the effect of wage on labor supply cannot be 
completely captured by a single variable. The shape of the age-wage profile matters as much as the average level of wages over the lifetime (Lazear 1976; 1986). For example, holding average wages over the lifetime constant, individuals whose wages decline faster with age are likely to retire earlier. Figures 1 and 2 depicts how education and place of birth shift the age-earnings profile. ${ }^{12}$ In Figure 1 it can be observed that people with 11 or more years of schooling tend to have higher earnings than people with less than 11 years of education, and the slopes of the earnings profiles for these two groups are generally the same. ${ }^{13}$ Figure 2 shows, on the other hand, that the shape of the earnings profile varies with the place of birth. Although the local born population have higher earnings, their earnings decline more rapidly with age compared to people born in China. For people born in Hong Kong, therefore, the steeper negative slope of the age-earnings profile will induce a greater intertemporal substitution effect that tends to encourage earlier retirement. This may explain why the variable hk has a negative coefficient in the retirement age equation. ${ }^{14}$ On the other hand, the school variable does not tilt the slope of earnings profile, and its effect on the retirement age is positive.

[Figures 1 and 2 about here]

Another factor that may account for the differing effects of education versus place of birth is that education requires prior investments in human capital. From a life cycle perspective, therefore, a person with higher education does not necessarily have a higher lifetime wealth than one with lower education (e.g., Lindsay 1971). There will be a substitution effect but little wealth effect on labor supply. People who are born in Hong Kong, on the other hand, are likely to be endowed with a higher present value of lifetime earnings than those born in China. If this is true, the wealth effect will cause the Hong Kong born to retire earlier.

Using the estimated coefficients from the first four columns of Table 5, the mean retirement age is estimated to be 67.04 (s.e. $=0.32$ ) for 1976, $67.36(0.26)$ for 1981, 66.38 (0.22) for 1986, and 65.33 (0.21) for 1991. The values of these estimates are from four to twelve months lower than the non-parametric estimates shown in Table 4, but they reveal a similar pattern of the change in mean retirement age over time. Notice also that 
the estimated standard deviation of the retirement age is over eight years. Among the 1991 population, for example, a 95 percent confidence interval for retirement age would cover the age range from 47.9 years to 82.3 years. Though the mean retirement age is estimated with some precision, the retirement age of an individual can only be predicted with a very large margin of error.

One way of assessing the goodness-of-fit of the censored regression model is to compare the predicted percentage of retired persons by age with the sample proportion, $p(A)$. Let $\mathcal{A}$ be the set of individuals at age $A$. Then the predicted percentage of retired persons at age $A$ is given by:

$$
\hat{p}(A)=\frac{1}{n(A)} \sum_{i \in \mathcal{A}} \Phi\left(\frac{A-X_{i} \hat{\beta}}{\hat{\sigma}}\right) .
$$

Figure 3 plots $p(A)$ and $\hat{p}(A)$ against age for the year 1991. The predicted percentage of retired persons tracks the sample proportion quite closely: the squared correlation between the two is 0.988 . The behavior of $\hat{p}(A)$ is much smoother than $p(A)$ beyond age 80 . This may reflect the fact that the sample proportion is a poor estimator of the true proportion of retired persons when the sample size is small. Notice also that $\hat{p}(A)$ is consistently below $p(A)$ for ages between 65 and 70, which indicates some misspecification of the model. ${ }^{15}$ The degree to which the model underestimates the proportion of retired person for those aged between 65 and 70 is, however, relatively small. Unlike the case in the United States, where the social security system induces a spike in the frequency distribution of retirement at age 65 (Burtless and Moffitt 1984), there is no such pronounced spike in the Hong Kong data.

[Figure 3 about here]

\section{Cohort Analysis}

When (censored) age is used as the dependent variable, cohort effects and year effects cannot be separately identified. It is therefore useful to study changes in retirement patterns by birth cohorts as well as changes in retirement patterns over time. Figure 4 plots the percent retired against age by different birth cohorts. The figure shows that those born between 1902 and 1911 had significantly lower retirement rates than those 
born in the following decade. The cohort effect is much more difficult to discern among the more recent cohorts. However observations of the behavior of these recent cohorts beyond age 65 are not yet available. If the cohort effect on retirement only shows up at old age, the present data set will not be able to reveal such effect for these recent cohorts.

[Figure 4 about here]

To arrive at a more quantitative measure of the cohort effect, and to remove the effects of other demographic variables, a cohort variable can be used in a censored regression model for retirement age. The regressions include all observations of individuals born in the 1902-1946 period. The variable cohort is defined as the year of birth minus 1901. Alternatively, dummy variables for different cohort groups can be used to capture the cohort effect. Table 6 shows the estimation results.

[Table 6 about here]

The estimated coefficients for the demographic variables in Table 6 are very similar to those in the last column of Table 5. More educated people are predicted to retire later than people with less schooling, while people born in Hong Kong generally retire earlier than people born in China. The variables hincome and house both show a negative income effect on labor supply, and married men are more likely to be retired than widowed, divorced, or single men. In column (1) of Table 6, the coefficient on cohort suggests that the retirement age shows a declining trend with successive cohorts. Holding demographic characteristics constant, the model predicts that people who were born a decade apart would have a difference in mean retirement age of about nine months (i.e., $0.077 \times 10 \times 12$ months).

Columns (2) and (3) of Table 6 shows that the decline in mean retirement age is not linear across the cohorts under study. The estimated cubic polynomial of cohort effect in column (2) is shown by the solid line (with the associated 95 percent confidence interval) in Figure 6. Estimated cohort effects using the dummy variables specification of column (3) is shown by the dotted line in the same figure. The mean retirement age declined sharply from 69.3 years for the 1902-1906 cohort to 65.9 years for the 1917-1921 cohort. 
The rate of decrease then decelerated, and the estimated mean retirement age for the $1942-1946$ cohort is 64.6 years.

[Figure 5 about here]

The actual differences in mean retirement age across birth cohorts is greater than the estimated cohort effects shown in Table 6 because individual characteristics also differ systematically across cohorts. For example the value of hincome is higher for later cohorts than for earlier cohorts. If the censored regression model in column (1) of Table 6 does not control for hincome, the size of estimated coefficient on cohort will increase (in absolute value) from 0.077 to 0.099. Similarly, if the censored regression model does not control for variations in home ownership across cohorts, the size of the estimated cohort effect will increase from 0.077 to $0.084 .{ }^{16}$ Therefore rising levels of non-wage income explains part (but not all) of the decline in retirement age across birth cohorts. Because of rising productivity, later birth cohorts have a higher lifetime wealth than earlier cohorts. The cohort effects estimated in this section may indicate the rising demand for leisure by later cohorts. ${ }^{17}$

\section{Summary}

This paper has attempted to provide an overview of retirement patterns in Hong Kong on the basis of limited data. Since there is no direct information about the date people retire, the retirement age has to be inferred from people's current age and their current

retirement status. Using a non-parametric method, the mean retirement age for the 1991 adult male population is estimated to be about 66 years.

A censored regression model is also developed to estimate the effect of covariates on the retirement age. This censored regression model is equivalent to a restricted probit model, and the estimated parameters have a straightforward interpretation. The results clearly show a negative income effect on the retirement decision. Men whose wives and children earn more are likely to retire earlier. Home ownership by the person's household is also negatively related to the retirement age. The effect of wage or earnings on retirement is less clear, partly because wage information is not available for the retired. 
For people aged over 40, years of schooling shifts up the age-earnings profile without significantly altering its slope, and schooling is found to delay retirement. Native born men have an age-earnings profile which is higher than and steeper than that of those born in China. Probably as a result of the steeper decline of earnings with age, men born in Hong Kong are found to retire earlier than Chinese born men.

The data shows substantial differences in retirement age across birth cohorts. Later cohorts have higher levels of non-wage income and wealth and are found to have a lower mean retirement age than earlier cohorts. After controlling for such personal characteristics, a substantial cohort effect remains. The data used in the study do not contain information about personal wage history or pension wealth, which are the obvious candidates for explaining the cohort effect. For policy purposes, understanding the effect of (public or private) pensions on the retirement decision is of primary significance. That has to await further research and, more importantly, better data. 


\section{Notes}

1 The figures quoted in this paragraph are obtained from Census and Statistics Department $(1972 ; 1992 ; 1994)$.

${ }^{2}$ For young adults, labor supply also adjusts through changes in school enrollment.

3 According to the census coding manual, a persons of independent means "lives by either renting a house or flat (or part of a house) or sub-letting it to others, or on capital accumulated in previous years, or on income from investments or on remittances from overseas" (Census and Statistics Department 1990). This description seem to fit a person who has saved enough for retirement. The proportion of such persons in the population is found to increase with age, which indicates that they may be behaviorally similar to those whose reason for not seeking work is "retirement." The conclusions of these paper are not materially affected when such persons are excluded.

${ }^{4}$ For sensitivity analysis, I also use a broader definition of retirement that includes men who were economically inactive because of "household duties" or "other reasons." The estimated mean retirement age falls by four to eight months but its time pattern remains unchanged.

${ }^{5}$ In 1991 the foreign born constituted less than 5 percent of the male population aged 40 or above. Many of them came to work in Hong Kong and would return to their home country to retire. The 1991 census shows that only 11 percent of foreign born males aged 40 or above were retired, while the corresponding figure for those born in Hong Kong or China is 26 percent. Census records in Hong Kong will not correctly reveal the retirement behavior of the foreign born.

${ }^{6}$ Evidence from the United States suggests that many "retired" men re-enter the labor force (Blau 1994). Data on labor market transitions are patchy in Hong Kong. In a special survey conducted by the Census and Statistics Department (1995), it was found that 1.4 percent of the male labor force participants aged 60 and over were not in the labor force a year ago. Some of these - but it is not known how many - were people who recovered from their illness. To the extent that retirement is not an absorbing state, 
the methods used here will underestimate the age at permanent withdrawal from the labor force.

7 Individuals aged 88 or above are treated as one group since some single-year age groups beyond age 88 contain no observations.

8 The normality assumption is not crucial for the argument.

${ }^{9}$ For unemployed or retired persons, no earnings data is available. Even for employed persons, only the current earnings at the time of the census are known. Moreover the data contain no information regarding industries and occupations for retired persons.

10 Household income and employment earnings are top-coded at HK\$99998. I assume income figures are log-normally distributed and estimate the mean and standard deviation of log household income and log employment earnings separately for each census year. Top-coded records are then imputed a value equal to the conditional mean of the respective distributions using Johnson and Kotz's (1970, p. 129) formula. Altogether about 6 percent of the records are subject to this adjustment. Income figures are expressed in 1000 Hong Kong (1991) Dollars. At the then prevailing exchange rate, one U.S. Dollar is equivalent to 7.8 Hong Kong Dollars.

11 Even in the presence of intra-family transfers, an individual cannot assume the entire hincome is his non-wage income. Similarly the house variable does not distinguish between home ownership by the individual or home ownership by other household members. These variables are therefore likely to underestimate the magnitude of the income effect on labor supply.

12 The profiles are estimated using only the sample of men not retired. They are obtained from a robust smoothing technique known as locally weighted smoothing scatterplots (Cleveland 1979). By using observations on working men only, these estimated profiles are potentially subject to the sample selection bias problem. In principle, this problem can be solved by a selection bias correction procedure. However the problem is ignored here because variables that enter into the selection equation are also likely to enter into the wage equation, which makes identification highly sensitive to functional 
forms (Mroz 1987).

13 Since the sample consists of elderly people who were born when Hong Kong was still relatively underdeveloped, only 23 percent of the observations had 11 or more years of education. The peak of the earnings profile occurs much earlier in Hong Kong than is typical of a developed economy such as the United States. Using cross section data in 1991, Suen (1996) finds that employment earnings peak at around 18 years after entry into the labor force. The decline in earnings after age 40 probably reflects rapid human capital obsolescence as well as a cohort effect.

14 The slower decline in the earnings of immigrants relative to natives near the end of their career is consistent with the finding that immigrants experience more rapid earnings growth than natives at the beginning of their working life in Hong Kong (Lam and Liu 1993). Both observations suggest that immigrants invest more heavily in their human capital. It is then plausible that immigrants wish to work longer to reap the returns from human capital investment. On this argument, the flatter slope of the immigrants' earnings profile is not an exogenous factor in their retirement decision, but is determined along with their retirement age.

15 If the logarithm of age is used instead as the censored dependent variable, the fit improves slightly but the model still under-predicts the percent retired in the 65 to 70 age group.

16 On the other hand, if the variable school is excluded, the estimated cohort effect will fall (in absolute value) to 0.074. The variables married and hk are found to have little effect on the coefficient on cohort.

17 Later cohorts also have a higher life expectancy than earlier cohorts due to improvements in medical technology. An increase in time endowment will increase the demand for consumption, which will result in an increase in labor supply. According to the estimates obtained here, such an effect is overwhelmed by the wealth effect. 


\section{References}

Berkovec J, Stern S (1991) Job Exit Behavior of Older Men. Econometrica 59 (1): $189-210$.

Boskin MJ (1977) Social Security and Retirement Decisions. Economic Inquiry 15 (1): $1-25$.

Burtless G, Moffitt R (1984) The Effect of Social Security Benefits on the Labor Supply

of the Aged. In: Aron H, Burtless G (eds) Retirement and Economic Behavior. Brookings Institution, Washington, 135-171.

Census and Statistics Department (1972) Hong Kong Population and Housing Census: 1971 Main Report. Government Printer, Hong Kong.

— (1987) Hong Kong Life Tables, 1971-2006. Government Printer, Hong Kong.

— (1990) Hong Kong 1991 Population Census: Coding Manual. Government Printer, Hong Kong.

— (1992) Hong Kong Population Projections: 1992-2011. Government Printer, Hong Kong.

— (1994) Hong Kong Annual Digest of Statistics: 1994 Edition. Government Printer, Hong Kong.

Cleveland WS (1979) Robust Locally Weighted Regression and Smoothing Scatterplots. Journal of American Statistical Association 74 (368): 829-836.

Cox DR, Oakes D (1984) Analysis of Survival Data. Chapman-Hall, London.

Gendell M, Siegel JS (1992) Trends in Retirement Age by Sex: 1950-2005. Monthly Labor Review 115 (2): 22-29.

Hurd MD, Boskin M (1984) The Effect of Social Security on Retirement Behavior. Quarterly Journal of Economics 98 (4): 767-790. 
Johnson NL, Kotz S (1970) Distributions in Statistics: Continuous Univariate Distributions 1. Wiley, New York.

Lam KC, Liu PW (1993) Are Immigrants Assimilating Better Now than a Decade Ago? The Case of Hong Kong. Hong Kong Institute of Asia-Pacific Studies, Hong Kong. (1995a) Labour Shortage in Hong Kong: Causes, Consequences and Policies. Asian Economic Journal 9 (1): 71-87.

— (1995b) Non-working Parents and Labor Force Participation of Married Women with Children. Working paper.

Lazear EP (1976) Age, Experience, and Wage Growth. American Economic Review 66 (4): $548-558$.

— (1986) Retirement from the Labor Force. In: Ashenfelter O, Layard R (eds) Handbook of Labor Economics, Vol. 1. North-Holland, Amsterdam, 305-355.

Lindsay CM (1971) Measuring Human Capital Returns. Journal of Political Economy 79 (6): 1195-1215.

Mitchell OS, Fields GS (1984). The Economics of Retirement Behavior. Journal of Labor Economics 2 (1): 84-105.

Mroz TA (1987) The Sensitivity of an Empirical Model of Married Women's Hours of Work to Economic and Statistical Assumptions. Econometrica 55 (4): 765-799.

Murray J (1972) Subjective Retirement. Social Security Bulletin 42 (1): 20-24.

Pencavel J (1986) Labor Supply of Men: A Survey. In: Ashenfelter O, Layard R (eds) Handbook of Labor Economics, Vol. 1. North-Holland, Amsterdam, 3-102.

Riemers C (1976) Is the Average Age at Retirement Changing? Journal of the American Statistical Association 71 (355): 552-558.

Rust J (1989) A Dynamic Programming Model of Retirement Behavior. In: Wise DA, (ed) The Economics of Aging. University of Chicago Press, Chicago, 359-398. 
— (1990) Behavior of Male Workers at the End of the Life Cycle: An Empirical Analysis of States and Controls. In: Wise DA (ed) Issues in the Economics of Aging. University of Chicago Press, Chicago, 317-379.

Slade FP (1987) Retirement Status and State Dependence: A Longitudinal Study of Older Men." Journal of Labor Economics 5 (1): 90-105.

Suen W (1994) Market-Procured Housework: The Demand for Domestic Servants and Female Labor Supply. Labour Economics 1 (3): 289-302.

— (1996) Employment and Labour Earnings. In: Ho HCY, Chau LC (eds) The Hong Kong Economy in Transition. Asian Research Service, Hong Kong, 119-134. 


\section{Table 1}

Distribution of Reasons for Not Seeking Work (aged 40 or above)

\begin{tabular}{lrr}
\hline & Male & Female \\
\hline (a) temporary sickness/injury & 7.62 & 3.67 \\
(b) household duty & 2.47 & 53.46 \\
(c) studying & 0.02 & 0.00 \\
(d) of independent means & 0.87 & 0.64 \\
(e) retirement (including pensioner) & 83.80 & 39.59 \\
(f) inmates of institutions & 1.14 & 0.39 \\
(g) others & 4.09 & 2.25 \\
\hline
\end{tabular}

Figures are based on author's tabulation from the $1991 \mathrm{Popu}-$ lation Census five percent random sample file. The figures may not add up to 100 percent due to rounding. 
Table 2

Percent Retired by Age

\begin{tabular}{lrrrr}
\hline Age Group & 1976 & 1981 & 1986 & 1991 \\
\hline $40-44$ & 0.42 & 0.33 & 0.09 & 0.25 \\
$45-49$ & 2.09 & 1.10 & 1.15 & 1.33 \\
$50-54$ & 5.70 & 2.78 & 4.07 & 4.88 \\
$55-59$ & 12.02 & 12.68 & 14.52 & 15.22 \\
$60-64$ & 32.77 & 30.25 & 36.03 & 34.00 \\
$65-69$ & 52.24 & 54.11 & 57.77 & 61.01 \\
$70-74$ & 68.45 & 68.90 & 72.80 & 78.05 \\
$75-79$ & 83.33 & 79.17 & 86.31 & 87.91 \\
$80-84$ & 89.74 & 82.43 & 92.31 & 92.11 \\
$85-89$ & 90.91 & 95.83 & 94.59 & 94.44 \\
$90+$ & 80.00 & 100.00 & 100.00 & 100.00 \\
$40+$ & 15.81 & 17.76 & 22.80 & 25.63 \\
\hline
\end{tabular}

Figures are derived from the one percent random sample files of the 1976, 1981, 1986 and 1991 population censuses. 
Table 3

Decomposition of Changes in Percent Retired

\begin{tabular}{lccc}
\hline Period & $\begin{array}{c}(1) \text { due to } \\
\text { population structure }\end{array}$ & $\begin{array}{c}(2) \text { due to } \\
\text { retirement rates }\end{array}$ & Overall Change \\
\hline $1976-1981$ & 2.89 & -0.94 & 1.95 \\
$1981-1986$ & 3.07 & 1.97 & 5.04 \\
$1986-1991$ & 2.07 & 0.77 & 2.84 \\
$1976-1991$ & 8.47 & 1.35 & 9.82 \\
\hline
\end{tabular}

Column (1) is calculated from the expression $\sum\left(s_{i t}-s_{i \tau}\right) r_{i t}$, where $s_{i t}$ and $r_{i t}$ are the share of the population in age-group $i$ and the corresponding age-specific retirement rate. Column (2) is calculated as $\sum\left(r_{i t}-r_{i \tau}\right) s_{i \tau}$. Figures are denoted in percentage points. 
Table 4

Estimates of Retirement Age and Length of Working Life

\begin{tabular}{lcccc}
\hline Age Group & 1976 & 1981 & 1986 & 1991 \\
\hline (1) mean retirement age & 67.76 & 68.17 & 66.71 & 66.34 \\
& $(0.42)$ & $(0.34)$ & $(0.25)$ & $(0.24)$ \\
(2) mean age at labor force entry & 13.36 & 13.56 & 13.88 & 14.21 \\
& $(0.03)$ & $(0.03)$ & $(0.03)$ & $(0.03)$ \\
(3) average length of working life [(1) - (2)] & 54.40 & 54.61 & 52.83 & 52.13 \\
& $(0.42)$ & $(0.34)$ & $(0.25)$ & $(0.24)$ \\
(4) average life expectancy & 74.86 & 77.04 & 78.35 & 79.29 \\
(5) average length of retirement life $[(4)-(1)]$ & 7.10 & 8.87 & 11.64 & 12.95 \\
\hline
\end{tabular}

The age at labor force entry is defined to be $\max$ schooling $+6,12\}$. Average life expectancy is calculated as the weighted average of the age-specific life expectancies from life tables (Census and Statistics Department 1987). Standard errors are shown in parentheses. 


\section{Table 5}

Censored Regressions of Retirement Age, Using Age and Retirement Status, By Census Years

\begin{tabular}{|c|c|c|c|c|c|}
\hline Variable & 1976 & 1981 & 1986 & 1991 & $1976-91$ \\
\hline constant & $\begin{array}{l}67.558 \\
(0.734)\end{array}$ & $\begin{array}{l}67.300 \\
(0.629)\end{array}$ & $\begin{array}{l}66.329 \\
(0.536)\end{array}$ & $\begin{array}{l}64.233 \\
(0.543)\end{array}$ & $\begin{array}{l}65.023 \\
(0.334)\end{array}$ \\
\hline school & $\begin{array}{l}-0.011 \\
(0.058)\end{array}$ & $\begin{array}{c}0.084 \\
(0.050)\end{array}$ & $\begin{array}{c}0.111 \\
(0.045)\end{array}$ & $\begin{array}{c}0.285 \\
(0.043)\end{array}$ & $\begin{array}{c}0.138 \\
(0.024)\end{array}$ \\
\hline hk & $\begin{array}{l}-1.679 \\
(0.700)\end{array}$ & $\begin{array}{l}-1.856 \\
(0.591)\end{array}$ & $\begin{array}{l}-1.433 \\
(0.500)\end{array}$ & $\begin{array}{c}0.187 \\
(0.469)\end{array}$ & $\begin{array}{l}-1.015 \\
(0.271)\end{array}$ \\
\hline hincome & $\begin{array}{l}-0.044 \\
(0.013)\end{array}$ & $\begin{array}{l}-0.088 \\
(0.017)\end{array}$ & $\begin{array}{l}-0.208 \\
(0.020)\end{array}$ & $\begin{array}{l}-0.121 \\
(0.013)\end{array}$ & $\begin{array}{l}-0.097 \\
(0.007)\end{array}$ \\
\hline house & $\begin{array}{l}-2.058 \\
(0.534)\end{array}$ & $\begin{array}{l}-1.043 \\
(0.460)\end{array}$ & $\begin{array}{l}-0.552 \\
(0.394)\end{array}$ & $\begin{array}{l}-0.892 \\
(0.377)\end{array}$ & $\begin{array}{l}-1.055 \\
(0.213)\end{array}$ \\
\hline married & $\begin{array}{c}0.514 \\
(0.716)\end{array}$ & $\begin{array}{c}0.692 \\
(0.611)\end{array}$ & $\begin{array}{c}1.326 \\
(0.523)\end{array}$ & $\begin{array}{c}0.502 \\
(0.533)\end{array}$ & $\begin{array}{c}0.686 \\
(0.288)\end{array}$ \\
\hline \multicolumn{6}{|l|}{ census dummies: } \\
\hline 1976 & & & & & $\begin{array}{c}1.034 \\
(0.286)\end{array}$ \\
\hline 1981 & & & & & $\begin{array}{l}1.860 \\
(0.270)\end{array}$ \\
\hline 1986 & & & & & $\begin{array}{c}0.979 \\
(0.253)\end{array}$ \\
\hline 1991 & & & & & - \\
\hline$\hat{\sigma}$ & $\begin{array}{c}9.400 \\
(0.274)\end{array}$ & $\begin{array}{c}8.897 \\
(0.234)\end{array}$ & $\begin{array}{c}8.544 \\
(0.204)\end{array}$ & $\begin{array}{c}8.647 \\
(0.195)\end{array}$ & $\begin{array}{c}8.782 \\
(0.109)\end{array}$ \\
\hline log-likelihood & -1610.0 & -1869.8 & -2235.5 & -2543.6 & -8315.3 \\
\hline number of observations & 5863 & 6740 & 7449 & 8306 & 28358 \\
\hline
\end{tabular}

Standard errors are shown in parentheses. 


\section{Table 6}

Censored Regressions of Retirement Age, Using Age and Retirement Status, By Birth Cohorts

\begin{tabular}{|c|c|c|c|}
\hline Variable & (1) & $(2)$ & (3) \\
\hline constant & $\begin{array}{l}67.202 \\
(0.384)\end{array}$ & $\begin{array}{l}70.793 \\
(0.758)\end{array}$ & $\begin{array}{l}64.366 \\
(0.818)\end{array}$ \\
\hline school & $\begin{array}{c}0.127 \\
(0.022)\end{array}$ & $\begin{array}{c}0.123 \\
(0.022)\end{array}$ & $\begin{array}{c}0.124 \\
(0.022)\end{array}$ \\
\hline hk & $\begin{array}{l}-1.036 \\
(0.252)\end{array}$ & $\begin{array}{l}-1.106 \\
(0.253)\end{array}$ & $\begin{array}{l}-1.115 \\
(0.255)\end{array}$ \\
\hline hincome & $\begin{array}{l}-0.088 \\
(0.007)\end{array}$ & $\begin{array}{l}-0.088 \\
(0.007)\end{array}$ & $\begin{array}{l}-0.089 \\
(0.007)\end{array}$ \\
\hline house & $\begin{array}{c}-0.969 \\
(0.198)\end{array}$ & $\begin{array}{l}-0.981 \\
(0.198)\end{array}$ & $\begin{array}{l}-0.995 \\
(0.199)\end{array}$ \\
\hline married & $\begin{array}{c}0.598 \\
(0.267)\end{array}$ & $\begin{array}{c}0.615 \\
(0.267)\end{array}$ & $\begin{array}{c}0.625 \\
(0.199)\end{array}$ \\
\hline cohort & $\begin{array}{l}-0.077 \\
(0.016)\end{array}$ & $\begin{array}{l}-0.595 \\
(0.112)\end{array}$ & \\
\hline $\operatorname{cohort} * * 2$ & & $\begin{array}{c}0.021 \\
(0.005)\end{array}$ & \\
\hline cohort $* * 3$ & & $\begin{array}{l}-2.38 \mathrm{e}-4 \\
(0.79 \mathrm{e}-4)\end{array}$ & \\
\hline \multicolumn{4}{|l|}{ cohort dummies: } \\
\hline $1902-06$ & & & $\begin{array}{c}4.671 \\
(0.988)\end{array}$ \\
\hline $1907-11$ & & & $\begin{array}{c}2.583 \\
(0.873)\end{array}$ \\
\hline $1912-16$ & & & $\begin{array}{l}1.704 \\
(0.815)\end{array}$ \\
\hline $1917-21$ & & & $\begin{array}{c}1.248 \\
(0.783)\end{array}$ \\
\hline $1922-26$ & & & $\begin{array}{c}0.505 \\
(0.762)\end{array}$ \\
\hline $1927-31$ & & & $\begin{array}{c}0.933 \\
(0.747)\end{array}$ \\
\hline $1932-36$ & & & $\begin{array}{c}0.701 \\
(0.748)\end{array}$ \\
\hline $1937-41$ & & & $\begin{array}{c}0.883 \\
(0.800)\end{array}$ \\
\hline $1942-46$ & & & - \\
\hline$\hat{\sigma}$ & $\begin{array}{c}8.014 \\
(0.156)\end{array}$ & $\begin{array}{c}8.009 \\
(0.156)\end{array}$ & $\begin{array}{l}8.068 \\
(0.155)\end{array}$ \\
\hline log-likelihood & -8166.9 & -8150.4 & -8151.6 \\
\hline number of observations & 26192 & 26192 & 26192 \\
\hline
\end{tabular}

Standard errors are shown in parentheses. 
Figure 1

Education and the Earnings Profile

1976

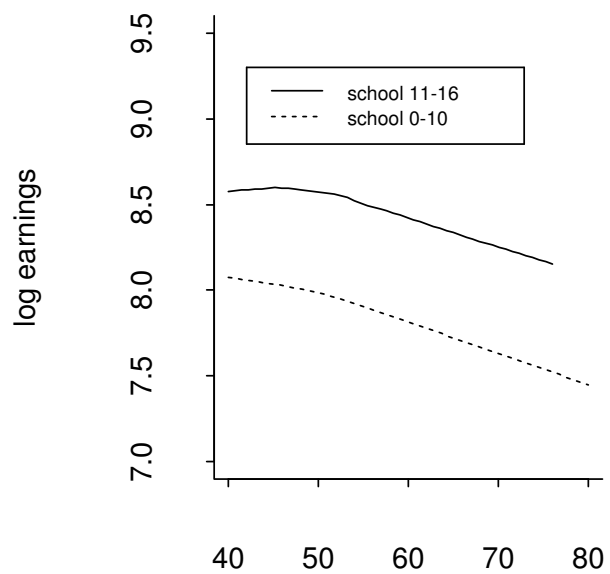

1986

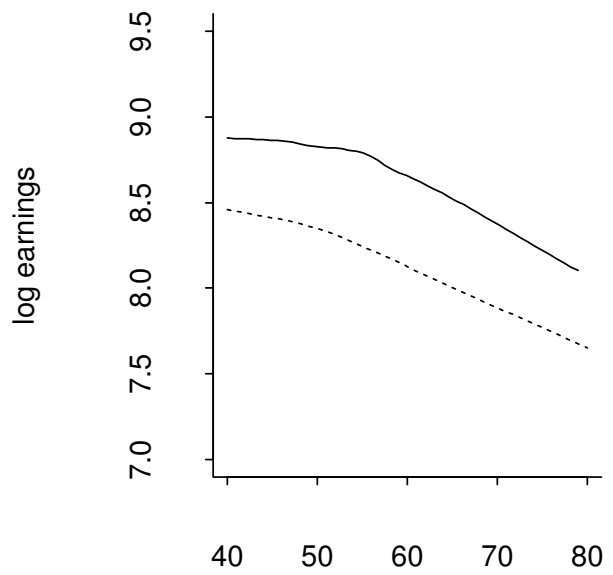

age
1981

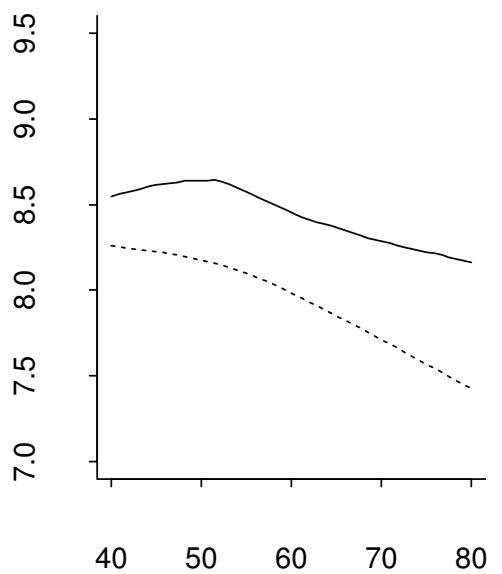

1991

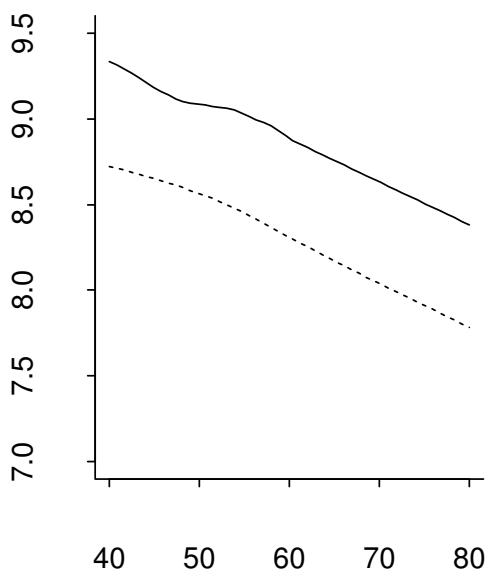

age 
log earnings
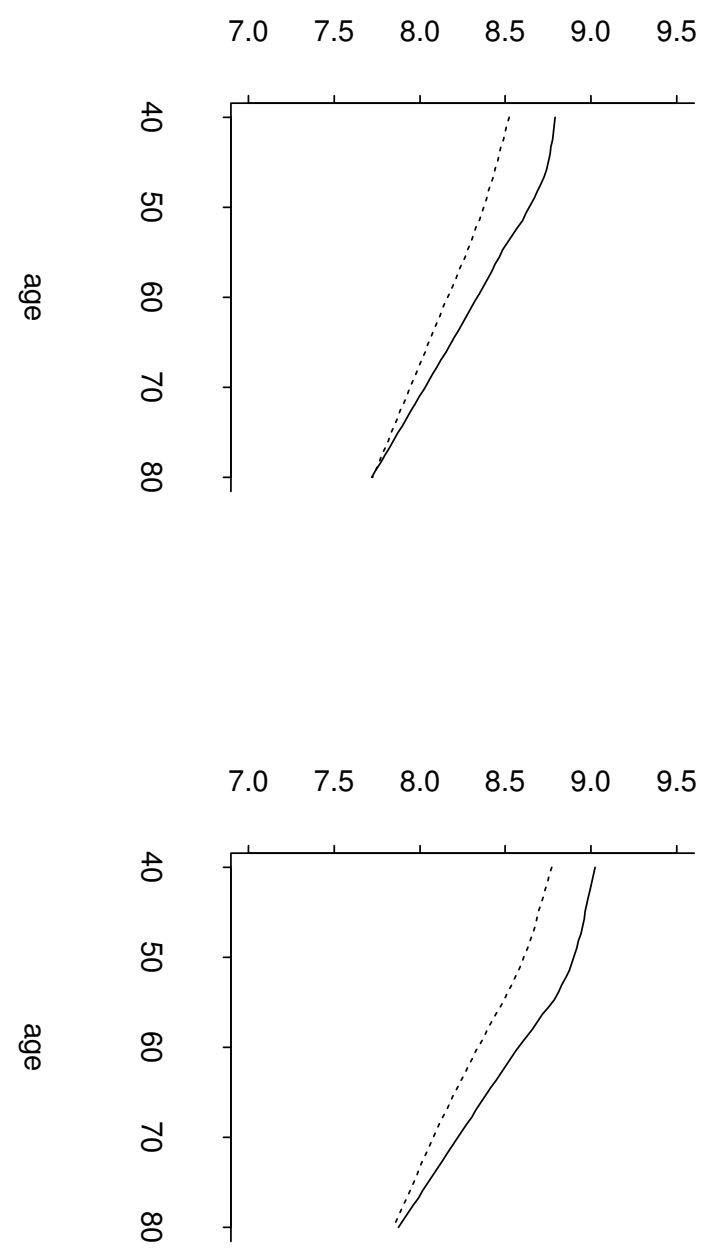

$\overrightarrow{\mathscr{D}}$

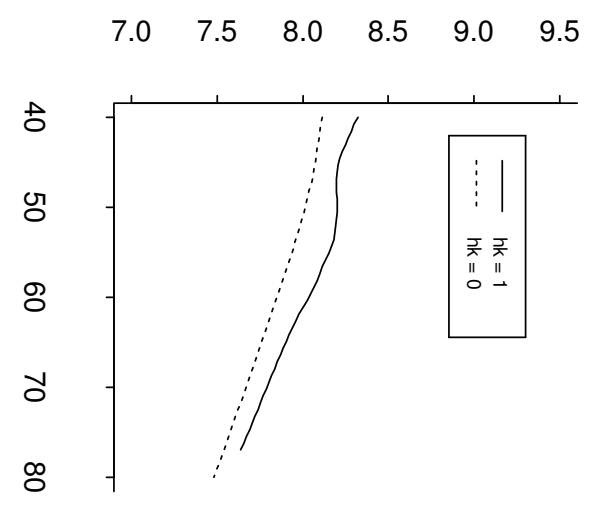

$\ddot{\emptyset}$

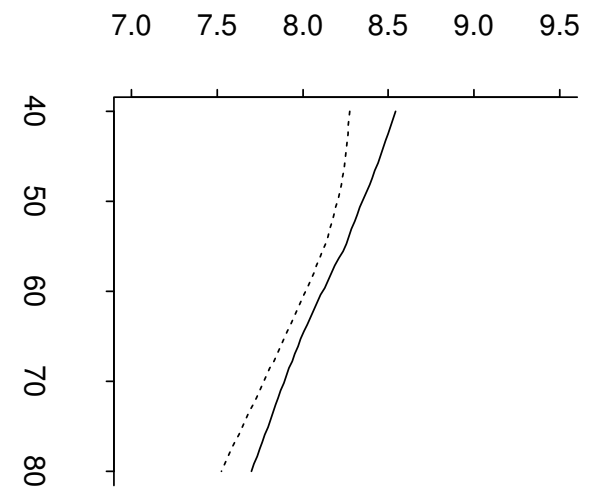

$\vec{\emptyset}$

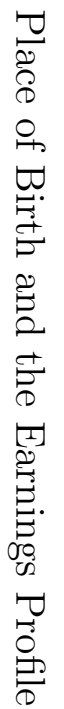

$\stackrel{\overrightarrow{0}}{\mathscr{O}}$ 


\section{Figure 3}

Actual and Predicted Percentage of Retired Persons, 1991

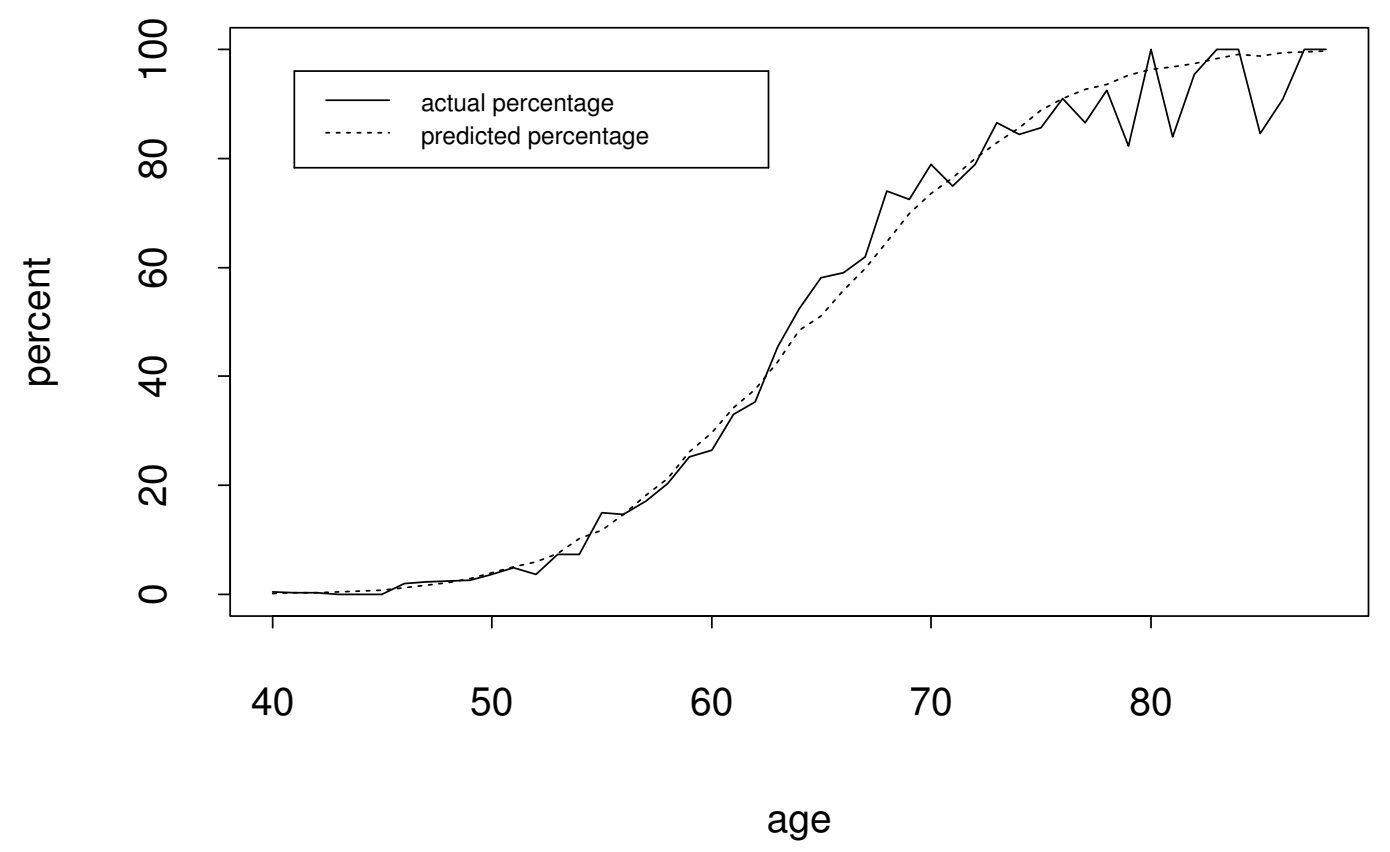


Figure 4

Percent Retired by Birth Cohort

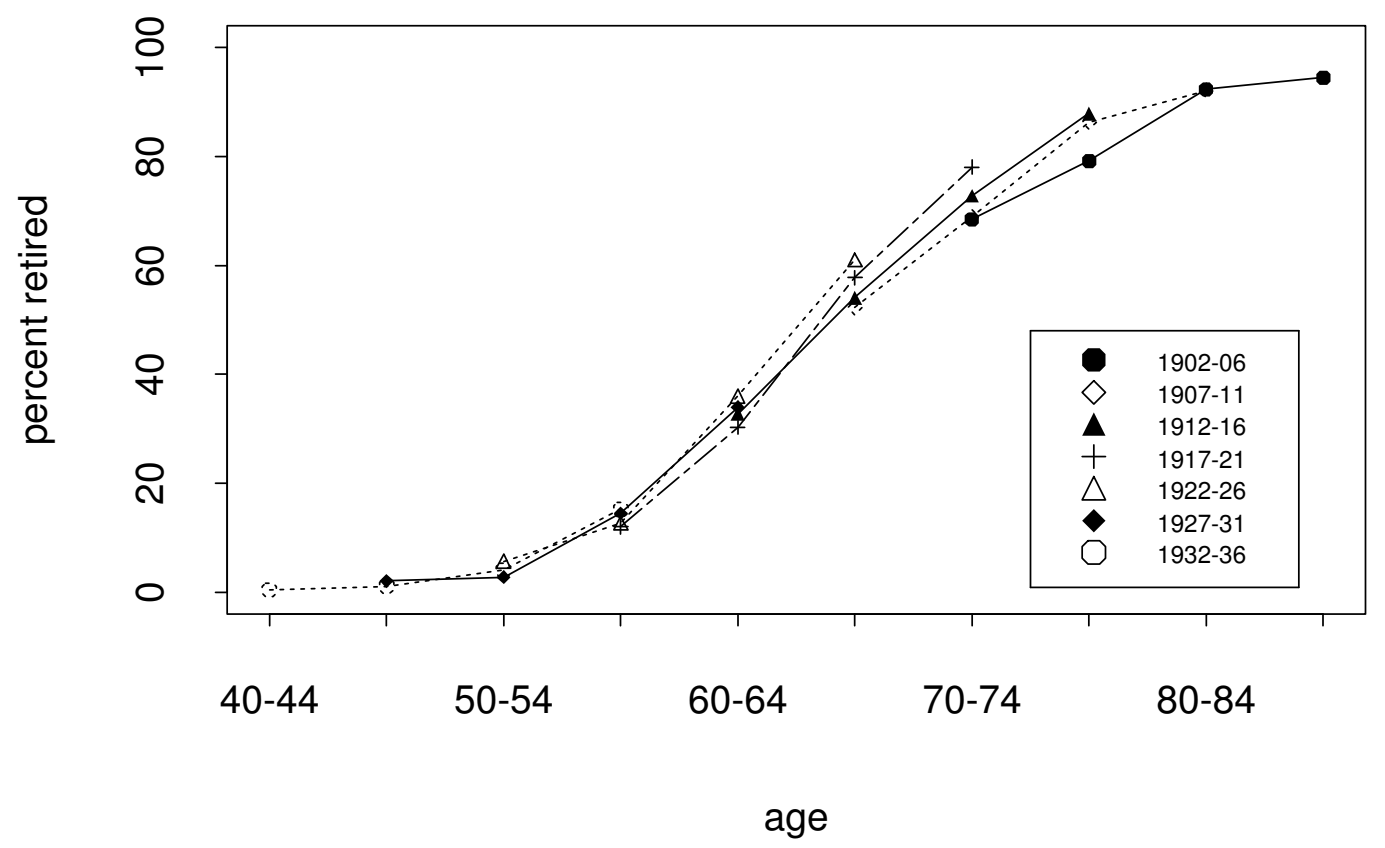


Figure 5

Estimated Cohort Effects on Retirement Age

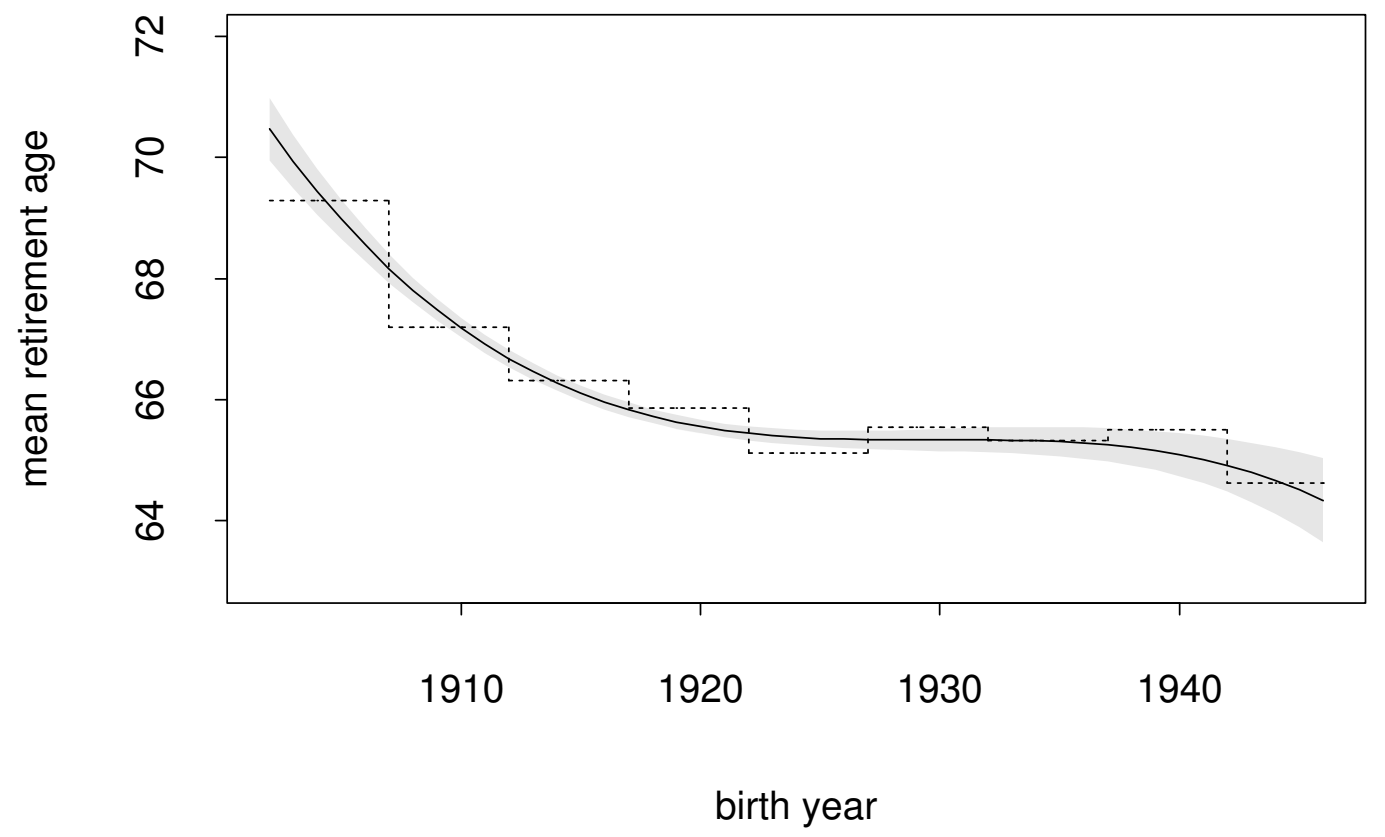




\title{
Retirement Patterns in Hong Kong: A Censored Regression Analysis
}

\author{
[Running Title: Retirement Patterns in Hong Kong]
}

\author{
Wing Suen* \\ School of Economics and Finance, The University of Hong Kong \\ Pokfulam Road, Hong Kong \\ Fax: +852 2548-1152 \\ E-mail: hrneswc@hkusua.hku.hk
}

Abstract. This paper provides an overview of retirement patterns in Hong Kong on the basis of limited data. A censored regression model is used to infer the retirement age from people's current retirement status and their current age. This model is equivalent to a restricted probit model, and the interpretation of parameters is straightforward. The results clearly show a negative income effect on the retirement decision. The retirement age seems to be positively related to lifetime earnings but negatively related to the rate of decline of earnings with age.

JEL classification numbers: C24, J14, J26

Key words: retirement age, probit model, cohort analysis

\footnotetext{
* I would like to thank Yoram Barzel, Richard Wong and two anonymous reviewers for their valuable comments.
} 